\title{
Fluoxetine Enhances Anti-tumor Activity of Paclitaxel in Gastric Adenocarcinoma Cells by Triggering Apoptosis and Necroptosis
}

\author{
TIN MYO KHING, WAH WAH PO and UY DONG SOHN \\ Laboratory of Signalling and Pharmacological Activity, Department of Pharmacology, \\ College of Pharmacy, Chung-Ang University, Seoul, Republic of Korea
}

\begin{abstract}
Background/Aim: Fluoxetine, an antidepressant, has cytotoxic effects on several cancer cell lines, while paclitaxel is an antineoplastic agent for various cancers. The aim of this study was to evaluate whether fluoxetine enhances the cytotoxic effect of paclitaxel in gastric adenocarcinoma cells and determine the mechanism of cell death. Materials and Methods: 3-(4,5-dimethylthiazol-2-yl)-2,5-diphenyltetrazolium bromide (MTT) assay was used to examine cell viability and perform cell cycle analysis. Annexin $V$ propidium iodide (PI) staining, 4',6-diamidino-2-phenylindole (DAPI) staining, caspase-3/7 assay, and western blot analysis were performed for determining cell death. Results: Fluoxetine enhanced the anti-proliferative effect of paclitaxel. Fluoxetine-paclitaxel combination caused $G_{2} / M$ arrest and increased events in the sub $G_{0} / G_{l}$ phase in a time and dose-dependent manner, indicating apoptotic cell death. Combination treatment caused an increase in early apoptotic and late apoptotic cell death compared to single treatment alone. Conclusion: Fluoxetine enhanced the antiproliferation effect of paclitaxel in gastric adenocarcinoma AGS cells and the combination caused cell death by triggering apoptosis and necroptosis.
\end{abstract}

According to WHO cancer statistics in 2018, gastric cancer is the sixth most common cancer and is responsible for one-third of cancer deaths. The percentage of cancer patients suffering from depression in the general population has increased from $5 \%$ to $20 \%$ (1). Antidepressants have been used to treat severe to moderate depression in cancer patients for the last 20-25 years (2). Paclitaxel is used as a first-line treatment for advanced diseases (breast, ovarian, and lung cancers), as

Correspondence to: Uy Dong Sohn, Professor, Ph.D., Department of Pharmacology, College of Pharmacy, Chung-Ang University, Seoul, 06974, Republic of Korea. Tel: +82 28205614, Fax: 011 +8228268752, e-mail: udsohn@cau.ac.kr

Key Words: Gastric adenocarcinoma cells, apoptosis, necroptosis. monotherapy or combination therapy (3). Numerous phase I and phase II trials have been reported, suggesting the potential effect of paclitaxel in treating advanced gastric cancers $(4,5)$. It inhibits microtubule depolymerization, causes cell cycle arrest at the $\mathrm{G}_{2} / \mathrm{M}$ phase and suppresses tumor growth (6). Paclitaxel has been reported to initiate apoptosis through multiple mechanisms, including an arrest of the cell cycle at the mitotic phase (7). Moreover, one study has reported that paclitaxel induces necroptosis in lung adenocarcinoma cells through $\mathrm{p}$-Casp8, receptor-interacting protein kinase 1 (RIPK1), and RIPK3 (8). Fluoxetine is an antidepressant belonging to the class of selective serotonin reuptake inhibitors (SSRIs) (9). It has been shown to inhibit the proliferation of different cancer cell lines $(10,11)$ and to cause cell cycle arrest in the G0/G1 phase in a time-dependent manner (12). Another study has revealed that fluoxetine induces apoptosis through extrinsic/intrinsic pathways and diminishes ERK/NF-kB-modulated anti-apoptotic and invasive potential in hepatocellular carcinoma cells in vitro (13).

Antitumor drugs act through different mechanisms of which programmed cell death (apoptosis) is highly conserved (14). The main morphologic criteria of apoptosis are cellular shrinkage, condensation and margination of nuclear chromatin, DNA fragmentation, cytoplasmic vacuolization, and cell lysis $(14,15)$. In addition to apoptosis, another form of programmed cell death, is necroptosis, which is characterized by a necrotic cell death morphology. Several DNA-damaging agents kill cancer cells by inducing necroptosis through the RIP1/RIP3/Mixed Lineage Kinase domain-Like (MLKL) pathway (16).

Several intracellular signaling pathways regulate complex processes such as development, proliferation, differentiation, response to stress, and apoptosis. The mitogen-activated protein kinase (MAPK) pathways participate not only in the regulation of cell proliferation, but also in the regulation of cell differentiation and death. In the Raf/MEK/ERK pathway, Erk1 and Erk2 have central roles in determining its physiological outputs (17) and play a critical role in cell 
survival, migration, and tumor invasion (18). Akt is a serine/threonine protein kinase that has been implicated in the pathogenesis of cancer as well as in essential cellular processes including metabolism, cell growth, proliferation, cell cycle progression, and survival (19). Poly (ADP-ribosylation) PARP catalyzes the transfer of ADP-ribose to target proteins and plays a crucial role in DNA repair and replication, transcription, and cell death. Necroptosis is executed through unique signaling pathways: the receptor interacting protein RIP1/RIP3-dependent pathway activated by extracellular stimuli such as tumor necrosis factor (TNF) and/or PARP-1 pathway triggered by continued DNA damage (20). In this study, we evaluated whether fluoxetine enhances the antiproliferative effect of paclitaxel in the gastric adenocarcinoma AGS cell line and examined the mechanism of its action in order to provide the theoretical and experimental basis for clinical applications and future research.

\section{Materials and Methods}

Materials. Paclitaxel was purchased from Sigma-Aldrich, (St. Louis, MO, USA) and fluoxetine hydrochloride was purchased from Selleckchem (Houston, TX, USA). Culture medium RPMI 1640, Dulbecco's Phosphate Buffered Saline (DPBS), antibiotic solutions and Fetal Bovine Serum (FBS) were purchased from Welgene Inc. (Gyeongsan, Republic of Korea). Trypsin-EDTA $0.25 \%$ was purchased from (ThermoFisher Scientific, Waltham, MA, USA). The 3-[4,5-dimethylthiazol-2-yl]-2,5-diphenyltetrazolium bromide (MTT) and dimethyl sulfoxide (DMSO) were also purchased from Sigma-Aldrich. The Anti-Erk, anti-p-Erk, anti-Akt, anti-p-Akt, anti-RIP3, anti-Bcl2, anti-DR4, anti-DR5, anti-PARP antibodies were purchased from Cell Signaling Technology (Danvers, MA, USA). Anti-cyclin B1 antibody was purchased from Novus Biologicals (CO, USA). Anti-actin antibody was purchased from Santa Cruz Biotechnology (Santa Cruz, CA, USA). Goat anti-rabbit IgG-HRP and goat anti-mouse IgG-HRP antibodies were purchased from Bethyl Laboratories (Montgomery, TX, USA). Enhanced chemiluminescence (ECL) solutions and Acrylamide were purchased from Elpis Biotechnology (Daejeon, Republic of Korea) and protein marker was purchased form Bio-Rad (Hercules, CA, USA). Propidium iodide and the Annexin $\mathrm{V}$ staining kits were purchased from Abcam (Cambridge, UK). Propidium iodide and the RNase solutions were purchased from Thermo Fisher Scientific (Eugene, Oregon, USA). The caspase-3/7 activity kit was purchased from Promega (Seoul, Republic of Korea).

Cell culture. The human gastric cancer cell line AGS (gastric adenocarcinoma, KCLB 21739) was obtained from the Korean Cell Line Bank (Seoul, Republic of Korea). The AGS cells were grown in complete medium, consisting of Roswell Park Memorial Institute (RPMI) 1640 medium supplemented with $10 \%$ fetal bovine serum, $1 \%$ penicillin-streptomycin, and $0.1 \%$ amphotericin $\mathrm{B}$ at $37^{\circ} \mathrm{C}$ in a humidified atmosphere of $5 \% \mathrm{CO}_{2}$ and $95 \%$ air. The cells were seeded and cultured until they reached $80 \%$ confluency.

Cell viability assay. The effect of different concentrations of paclitaxel or fluoxetine alone or in combination on cell growth were analyzed using the MTT assay. Briefly, $1 \times 10^{5}$ cells per well were seeded in a 24 -well plate and incubated at $37^{\circ} \mathrm{C}$ for $24 \mathrm{~h}$ until they reached $80 \%$ confluency. After exposure to the indicated concentrations of drugs for $24 \mathrm{~h}$ and $48 \mathrm{~h}$, the medium was discarded and $200 \mu \mathrm{l}$ of MTT solution $[0.5 \mathrm{mg} / \mathrm{ml}$ in phosphate buffered saline (PBS)] were added to each well and incubated for an additional $4 \mathrm{~h}$ at $37^{\circ} \mathrm{C}$ in a $5 \% \mathrm{CO}_{2}$ incubator. Media were removed and $200 \mu \mathrm{l}$ of DMSO were added to each well to solubilize formazan crystals (MTT metabolic product). The plates were shaken for $15 \mathrm{~min}$ to dissolve the crystals and $100 \mu \mathrm{l}$ of the solution were added to the 96-well microplate reader and the optical density was measured at $570 \mathrm{~nm}$. In vitro cytotoxic activity was evaluated by the calculation of the concentration of the drug required to kill $50 \%$ of cells relative to the untreated cultures, known as the half maximal inhibitory concentration $\left(\mathrm{IC}_{50}\right)$.

Cell cycle analysis. The AGS cells were treated with paclitaxel or fluoxetine alone or in combination for $6,12,24$ and $48 \mathrm{~h}$ as described above. Following treatment, cells were collected from culture plates using $0.25 \%$ trypsin, and rinsed with cold PBS. Subsequently, the cells were fixed with ice cold $70 \%$ ethanol and incubated at $4{ }^{\circ} \mathrm{C}$ overnight. The cells were subsequently re suspended in cold PBS and incubated with $1 \mathrm{ml}$ propidium iodide (PI) staining solution (containing $50 \mu \mathrm{g} / \mathrm{ml}$ propidium iodide and $50 \mu \mathrm{g} / \mathrm{ml} \mathrm{RNase} \mathrm{A)} \mathrm{at} 20$ $25^{\circ} \mathrm{C}$ for $25 \mathrm{~min}$ in the dark. The distribution of cells in each cell cycle phase was evaluated by flow cytometry (BD FACS Calibur, San Jose, CA, USA) using CellQuest Pro software.

Annexin V/PI assay. AnnexinV-fluorescein isothiocyanate (FITC)/Propidium iodide (PI) double staining kit was used to identify apoptotic cells and necrotic cells. The AGS cells were treated with different concentrations of paclitaxel and fluoxetine for 24 and $48 \mathrm{~h}$. After incubation, cells were harvested and resuspended in $500 \mu \mathrm{l}$ binding buffer, and then stained with $5 \mu \mathrm{l}$ of Annexin VFITC and $5 \mu \mathrm{l}$ of PI in the dark for $10 \mathrm{~min}$. The apoptotic and necrotic cells were detected using the FL1 and FL2 detector by flow cytometry (BD FACS Calibur). The non-treated group was used as a negative control. Cells showing up as Annexin $\mathrm{V}^{-} / \mathrm{PI}^{-}$were recognized as healthy cells, Annexin $\mathrm{V}^{-} / \mathrm{PI}^{+}$were recognized as necrotic cells (post-apoptotic necrosis or late apoptosis), and Annexin $\mathrm{V}^{+} / \mathrm{PI}^{-}$were considered as early apoptotic cells.

DAPI staining. The cells were washed with PBS and fixed with $4 \%$ paraformaldehyde in PBS for $30 \mathrm{~min}$ at room temperature. The fixed cells were washed again with PBS and stained with 4,6diamidino-2-phenylindole (DAPI, Sigma-Aldrich) solution for 2 min at room temperature. The cells were washed two more times with PBS and analyzed using a fluorescence microscope (Leica, Wetzlar, Germany).

Electrophoresis and western blotting. In brief, from each sample, 20 $\mu \mathrm{g}$ of protein/lane were separated on $8-15 \%$ SDS-PAGE and electroblotted onto nitrocellulose membranes. Subsequently, membranes were incubated for $1 \mathrm{~h}$ in a solution containing Tris buffered saline with Tween 20 (TBST) supplemented with 5\% nonfat dry milk or bovine serum albumin (BSA) and kept overnight at $4{ }^{\circ} \mathrm{C}$ by incubating with the primary antibody in dilutions ranged from 1:500 to 1:2000. Membranes were washed in Tris-buffered saline [10 $\mathrm{mM}$ Tris- $\mathrm{HCl}$ ( $\mathrm{pH} 8.0), 0.15 \mathrm{M} \mathrm{NaCl}$, and $0.05 \%$ Tween 20] followed by horseradish peroxidase-conjugated goat anti-mouse or goat anti- 



Figure 1. Effects of the treatment with paclitaxel (Pac) or fluoxetine (Flu) alone or in combination on the viability and morphology of AGS cells. AGS cells were treated with different concentrations of paclitaxel alone or in combination with fluoxetine for $24 h$ and $48 h$, and MTT assay was conducted to determine cell viability. (A) The graph shows the percentage of viable cells compared to that in the non-treated group. (B) Cell morphology was observed by light microscopy after single or combination treatment for $24 h$ and $48 h$ (magnification $\times 20$ ). a, g: non-treated; $b$, $h: 10 \mu M$ fluoxetine; $c, i: 20 \mathrm{nM}$ paclitaxel; $d, j: 40 \mathrm{nM}$ paclitaxel; $e, k: 10 \mu \mathrm{M}$ fluoxetine $+20 \mathrm{nM}$ paclitaxel; $f, l: 10 \mu \mathrm{M}$ fluoxetine $+40 \mathrm{nM}$ paclitaxel. All data are presented as mean \pm S.E.M, $n=3$; were analyzed using a one-way ANOVA test; $(* p<0.05$, ***p<0.001 compared with the non-treated group, ${ }^{\#} p<0.05,{ }^{\# \#} p<0.01,{ }^{\# \#} p<0.001$ compared with the single treatment group).

rabbit antibody. Biorad Universal Hood II Gel doc system (Hercules, CA, USA) was used for detection, and protein expression was quantified by Quantity One software (Bio-Rad). Protein loading equivalence was corrected in relation to the expression of actin.

Bioluminescent assays for caspase-3/7 activities. Caspase-3/7 activities were assayed in triplicates using assay kit Caspase-Glo ${ }^{\circledR}$ (Promega, Madison, WI, USA) on a white 96-well microplate. A total of $1 \times 10^{4}$ cells were seeded per well and incubated with different concentrations of paclitaxel and fluoxetine for $24 \mathrm{~h}$. Caspase activities were investigated according to the manufacturer's protocol. Briefly, $100 \mu$ l Caspase-Glo reagent were added and the contents of wells were gently mixed using a plate shaker for $30 \mathrm{sec}$ and incubated at room temperature for $1 \mathrm{~h}$. The luminescence of each sample was measured by the Flex station 3 Multimode plate reader (Molecular Devices, Sunnyvale, CA, USA).

Statistical analysis. All data were expressed as the mean \pm S.E.M. of at least three independent experiments. Statistical significance of differences among the groups were analyzed by one-way ANOVA test. Values of $p<0.05$ were considered to indicate statistically significant differences.

\section{Results}

Fluoxetine enhances the sensitivity of AGS cells to paclitaxel treatment. To determine the cytotoxic effect of Paclitaxel, AGS cells were treated with $10,20,40$, and $80 \mathrm{nM}$ of paclitaxel for $24 \mathrm{~h}$. Thereafter, cell viability was evaluated by the MTT cell viability assay. The growth of AGS cells was inhibited by paclitaxel in a dose-dependent manner. The cytotoxic effect began at $10 \mathrm{nM}$ and the $\mathrm{IC}_{50}$ value was $40 \mathrm{nM}$. The effect of fluoxetine on proliferation was evaluated using the MTT assay following treatment with $5,10,15,20$ and $30 \mu \mathrm{M}$ of fluoxetine. Treatment with $5 \mu \mathrm{M}$ fluoxetine for $24 \mathrm{~h}$, did not affect viability of AGS cells but at $10 \mu \mathrm{M}$, the viable cells were slightly decreased and reached less than $40 \%$ at $15 \mu \mathrm{M}$. To examine the potential synergistic or antagonistic interaction between fluoxetine and paclitaxel, AGS cells were treated with three different concentrations of paclitaxel, either alone or in combination with $10 \mu \mathrm{M}$ fluoxetine, for $24 \mathrm{~h}$ and $48 \mathrm{~h}$ and MTT assays were performed. The results described in Figure 
A

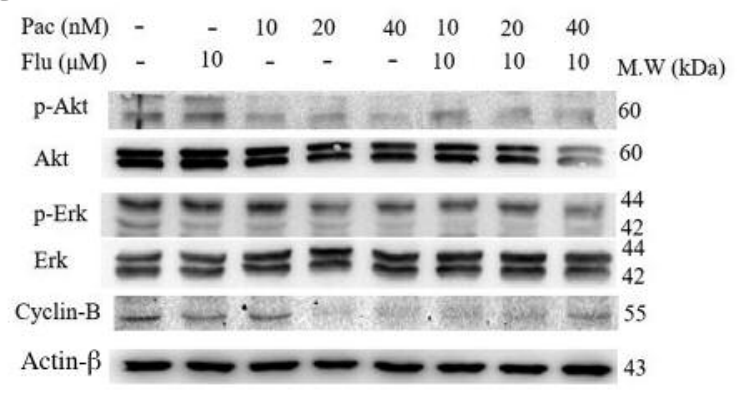

B

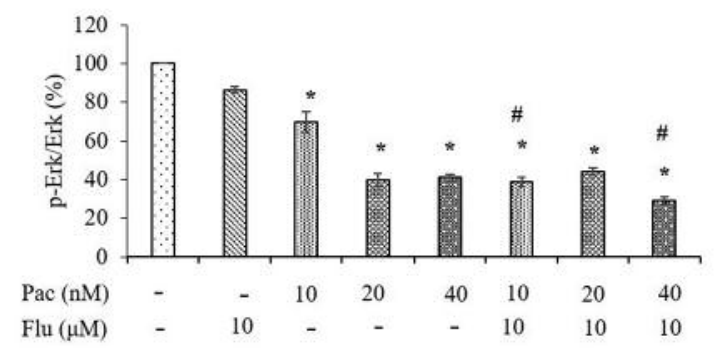

Figure 2. Effect of paclitaxel (Pac) and fluoxetine (Flu) on the expression of cell proliferation-associated proteins in AGS cells. (A) AGS cells were treated with $10 \mathrm{nM}, 20 \mathrm{nM}$, and $40 \mathrm{nM}$ paclitaxel alone or in combination with $10 \mu \mathrm{M}$ fluoxetine for $24 \mathrm{~h}$ and the expression levels of $A k t, p-A k t$, Erk, $p$-Erk, and Cyclin-B1 were determined by western blot analysis. $\beta$-Actin was used as the loading control. (B) The blots of Erk and p-Erk protein expression were quantified by densitometry. The data are presented as mean $\pm S . M . E, n=3$; they were analyzed using a one-way ANOVA test $\left({ }^{*} p<0.05\right.$ compared with the non-treated group and ${ }^{\#} p<0.05$ compared with the single treatment group).

1 indicated that treatment of cells with 10,20 and $40 \mathrm{nM}$ of paclitaxel combined with $10 \mu \mathrm{M}$ fluoxetine decreased from $90.0 \%$ to $70.0 \%$, from $65.0 \%$ to $40.0 \%$ and from $50.0 \%$ to $30.0 \%$, respectively compared to paclitaxel treatment alone at $24 \mathrm{~h}$ and from $60.0 \%$ to $30.0 \%$, from $50.0 \%$ to $20.0 \%$ and from $30.0 \%$ to $10.0 \%$ at $48 \mathrm{~h}$ (Figure $1 \mathrm{~A})$.

Simultaneous treatment of AGS cells with $10 \mu \mathrm{M}$ fluoxetine and 10, 20 and $40 \mathrm{nM}$ of paclitaxel for $24 \mathrm{~h}$ and $48 \mathrm{~h}$ resulted in significant alterations in cell morphology. Untreated AGS cells are polygonal with a homogeneous size distribution. Paclitaxel and fluoxetine treated cells were more suspended round shaped cells and the attached cells had increased size (Figure 1B).

Paclitaxel and fluoxetine act synergistically to inhibit the proliferation of AGS cells. To confirm the cell viability results, western blot analysis was performed to detect the cell proliferation protein markers, Erk 1/2, Akt, and cell cycle checkpoint protein indicator, cyclin B1. Phoshporylation of Erk1/2 was significantly decreased following treatment with the combination of 10 and $40 \mathrm{nM}$ paclitaxel and $10 \mu \mathrm{M}$ fluoxetine compared to that following treatment with paclitaxel alone $(p<0.05)$ (Figure 2B). Moreover, Akt was also inactivated and the phosphorylation of Akt decreased following single and combination treatment, but there was no statistically significant difference between the combination treatment and the single treatment $(\mathrm{p}>0.05)$. Moveover, activation of cyclin B1 was decreased upon treatment with $20 \mathrm{nM}$ and $40 \mathrm{nM}$ paclitaxel alone and upon combination treatment with fluoxetine (Figure 2A).

Determination of cell cycle arrest. To access the distribution of cells in the different phases of cell cycle and the extent of cell death, AGS cells were treated with paclitaxel alone or the combination of paclitaxel and fluoxetine for 6, 12, 24 and $48 \mathrm{~h}$,. The cells were collected, stained with PI and analyzed using flow cytometry. The results showed that the sub $\mathrm{G}_{0} / \mathrm{G}_{1}$ DNA content was significantly increased at $24 \mathrm{~h}$ and $48 \mathrm{~h}$ of combination treatment relative to single treatment $(p<0.05)$ (Figure 3B). Treatment with different concentrations of fluoxetine alone, significantly increased in a dose-dependent manner the cell population in the $\mathrm{G}_{0} / \mathrm{G}_{1}$ phase and the sub $\mathrm{G}_{0} / \mathrm{G}_{1}$ phase compared to the non-treated group $(p<0.01)$.

In the case of different concentrations of paclitaxel alone, the cell population in the $\mathrm{G}_{2} / \mathrm{M}$ phase was increased in a dose- and time-dependent manner up to $24 \mathrm{~h}$ compared to the non-treated group. Following $48 \mathrm{~h}$ treatment with $40 \mathrm{nM}$ and higher concentrations of paclitaxel, the cell population in the $G_{2} / M$ phase was decreased and that in the sub $G_{0} / G_{1}$ phase was increased.

Fluoxetine enhances paclitaxel-induced apoptosis. Tretament of cells with $20 \mathrm{nM}$ and $40 \mathrm{nM}$ paclitaxel alone or in combination with $10 \mu \mathrm{M}$ fluoxetine, increased the number of apoptotic AGS cells, but fluoxetine treatment alone had a small effect at $24 \mathrm{~h}$. At $48 \mathrm{~h}$ of combination treatment, there was a greater increase in the number of apoptotic AGS cells, and most of the remaining cells showed chromatin condensation, nuclear fragmentation and increased nuclear size (Figure 4).

Thereafter, the apoptotic effect of paclitaxel and fluoxetine in AGS cells was examined following single or combination treatment using flow cytometry with Annexin V/PI doubled staining. The percentage of early apoptotic cells and late apoptotic cells increased two-fold and four-fold after the combination treatment for $24 \mathrm{~h}$, respectively, when compared to the single treatment group (Figure 5B).

To confirm the apoptotic effect of the combination treatment, cleaved PARP levels were evaluated by western blotting. Cleaved PARP levels were significantly increased upon treatment with $10 \mathrm{nM}$ and $40 \mathrm{nM}$ paclitaxel in combination with fluoxetine, compared to single treatment $(p<0.01$ and $p<0.05)$ (Figure 6A). Thereafter, caspase-3/7 


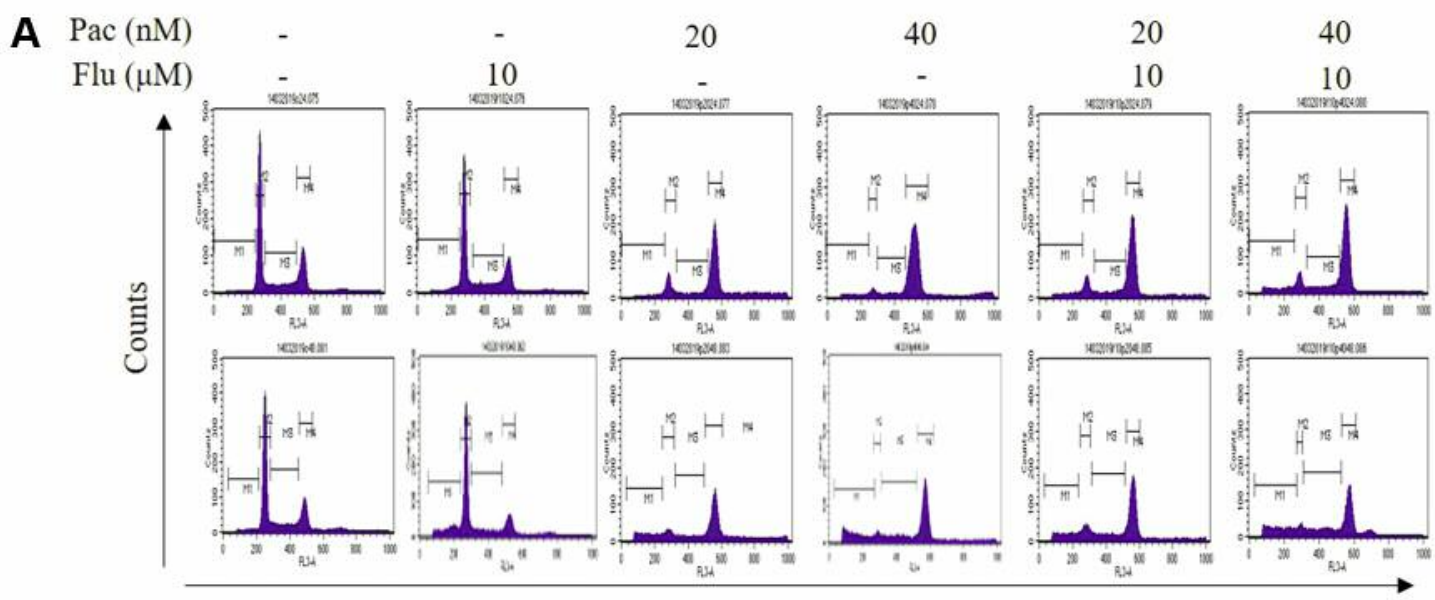

B

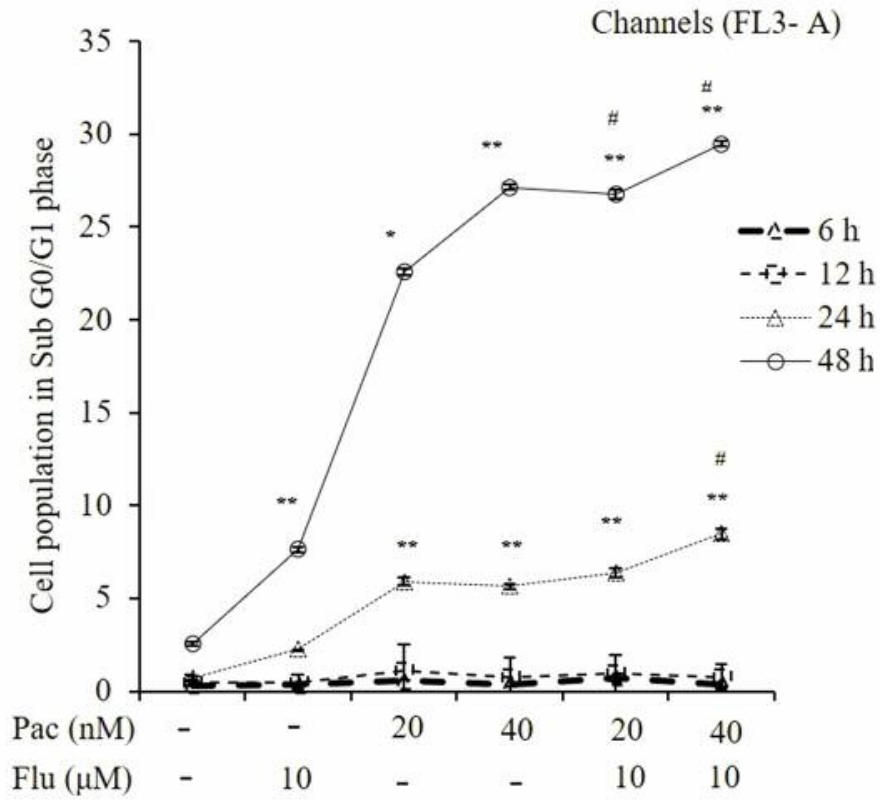

Figure 3. Effects of paclitaxel (Pac) and fluoxetine (Flu) on cell cycle distribution after single or combination treatment. (A) Cell-cycle distribution of AGS cells was analyzed following propidium iodide (PI) staining by flow cytometry (B) Sub $G_{0} / G_{1}$ phase was calculated by CellQuest Pro software, in which $M 1=S u b G_{0} / G_{1}$ phase, $M 2=G_{0} / G_{1}$ phase, $M 3=S$ phase, and $M 4=G_{2} / M$ phase. Data are presented as the mean $\pm S . E . M, n=3 ;$ were analyzed using a one-way ANOVA test $\left({ }^{* *} p<0.001,{ }^{* *} p<0.01\right.$ and ${ }^{*} p<0.05$ compared with the non-treated group, ${ }^{*} p<0.05$ compared with the single treatment group).

activity was also evaluated using a caspase-3/7 activity assay kit by measuring luminesence. Caspase activity was increased in the fluoxetine and paclitaxel combination treated group compared to the non-treated group and paclitaxel only treated group $(p<0.05)$ (Figure 6B).

The combination treatment caused an increase in DR5 protein expression compared to single treatment and the nontreated group. However, in the case of DR4 protein, there was no significant difference in its expression levels relative to the non-treated group (Figure 7). Bcl-2 protein expression decreased in single and combination treatment compared to the non-treated group. In case of the necroptotic protein marker, RIP3 protein, paclitaxel and the combination treated group showed a greater increase in protein expression compared to the non-treated group and single treated group (Figure 5C).

\section{Discussion}

Gastric cancer is predicted to be the fourth leading cancer causing mortality and the third leading cancer in women in Korea (21). A review has stated that $15.6 \%$ of cancer patients are prescribed antidepressants. Selective serotonin reuptake inhibitors are the most frequently prescribed antidepressants 


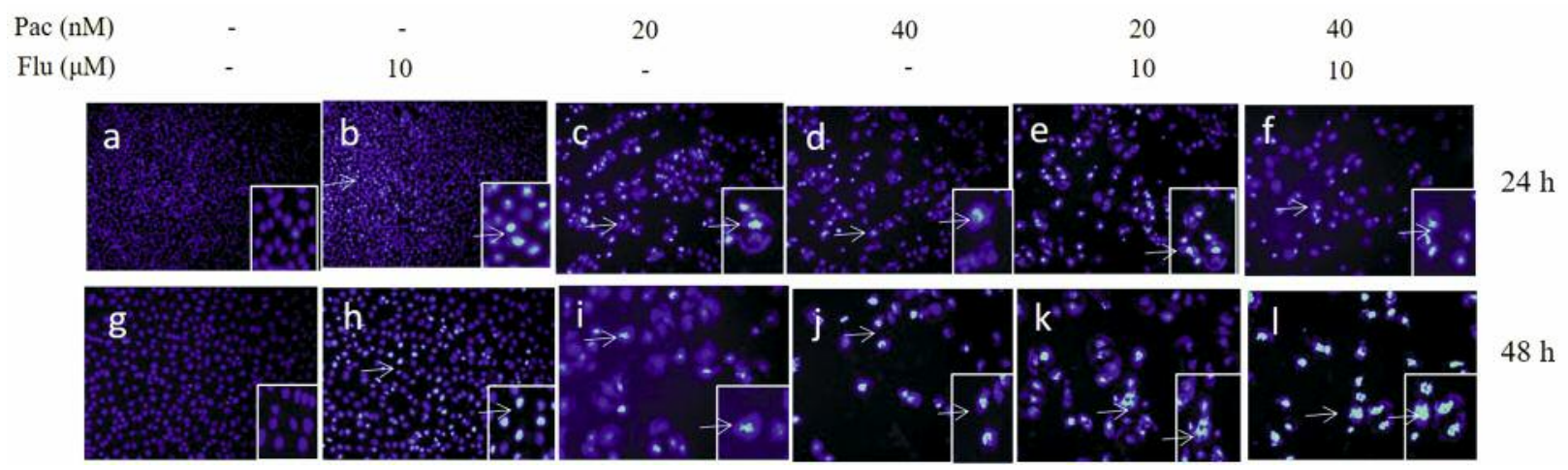

Figure 4. Assessment of the nuclear morphology using DAPI staining and fluorescence microscopy. AGS cells were treated with paclitaxel (Pac) and fluoxetine (Flu) alone or in combination for $24 \mathrm{~h}$ and $48 \mathrm{~h}$ before they were fixed and stained with DAPI. The stained nuclei were then observed under a fluorescence microscope using a blue filter magnification, ×20. a, g: non-treated; $b, h: 10 \mu M$ fluoxetine; c, $i: 20$ nM paclitaxel; d, $j: 40$ $n M$ paclitaxel; e, $k: 10 \mu \mathrm{M}$ fluoxetine $+20 \mathrm{nM}$ paclitaxel; $f, l: 10 \mu \mathrm{M}$ fluoxetine $+40 \mathrm{nM}$ paclitaxel. Micrographs are representative of three independent experiments. Arrowheads indicate the shrunken or fragmented nuclei with chromatin condensation.

(22), of which fluoxetine is one of the most commonly prescribed. Different studies have shown that fluoxetine has antiapoptotic effects against different cancer cell types (11, 13, 23). Paclitaxel is an antineoplastic agent widely studied in clinical trials of advanced gastric cancer as a single treatment or a combination treatment with other anticancer agents $(4,9,24)$. In the present study, the effect of paclitaxel in combination with fluoxetine on the viability and the mechanisms of death of AGS cells was evaluated by MTT assay, cell cycle analysis, DAPI staining, Annexin V/PI staining, and western blotting. Fluoxetine was not found to be toxic in AGS cells up to a concentration of $5 \mu \mathrm{M}$, following $24 \mathrm{~h}$ treatment. However, at $15 \mu \mathrm{M}$, cell viability decreased to $30 \%$ in comparison to that in the non-treated group. Consequently, fluoxetine was used at the concentration of $10 \mu \mathrm{M}$ in combination with paclitaxel in AGS cells. As for paclitaxel, three different concentrations $(10,20$, and $40 \mathrm{nM})$, that were less than the $\mathrm{IC}_{50}(50 \mathrm{nM})$, were used for $24 \mathrm{~h}$ to evaluate its cytotoxic effect on AGS cells. Based on the cell viability assay, fluoxetine enhanced the cytotoxic effect of paclitaxel on AGS cells (Figure 1). To verify the cell viability assay results, the levels of proteins related to cell proliferation and survival, Akt and Erk 1/2, were examined using western blot analysis. One study has reported that Akt phosphorylation and its transducing downstream events play a central role in cell survival and cell cycle progression at the $\mathrm{G}_{2}-\mathrm{M}$ transition phase and that paclitaxel inhibited Akt-Ser473 phosphorylation and induced mitotic arrest (25), which is consistent with our results. The combination treatment with paclitaxel and fluoxetine caused a significant decrease in p-Akt and p-Erk protein expression compared to single treatment and no-treatment. It was suggested that fluoxetine enhanced the antiproliferative effect of paclitaxel in the AGS cell line.
To investigate the possible mechanism by which fluoxetine enhances the cytotoxic effect of paclitaxel, we performed cell cycle analysis, DAPI staining, Annexin V/ PI staining, and western blot analysis. It has been previously reported that taxol is effective in inducing apoptosis at extremely low doses $(0.020-0.035 \mu \mathrm{M})$, in lung cancer cell lines (26), and this effective concentration was concurred in AGS cells in our study. In cell cycle analysis, fluoxetine treatment alone caused cell cycle arrest at the $\mathrm{G}_{0} / \mathrm{G}_{1}$ phase and induced apoptosis of cells in the sub $G_{0} / G_{1}$ phase in a dose- and time-dependent manner. Fluoxetine-induced apoptotic cell death may be attributed to cell cycle arrest at the $\mathrm{G}_{0} / \mathrm{G}_{1}$ phase. However, paclitaxel caused cell cycle arrest at the $\mathrm{G}_{2} / \mathrm{M}$ phase and cell death in a time- and dosedependent manner. This is in agreement with other studies showing rapid, dramatic effects of higher paclitaxel concentrations on mitosis and cell death that were originally believed to be responsible for its efficacy in cancer therapy (7). After treatment with paclitaxel and fluoxetine combination, the number of cells at the $\mathrm{G}_{2} / \mathrm{M}$ phase and sub $\mathrm{G}_{0} / \mathrm{G}_{1}$ phase increased (Figure 3 ). These results suggested that the effect of fluoxetine in sub effective doses did not overtake that of paclitaxel in cell cycle distribution.

According to DAPI staining and the caspase-3/7 activity assay, fluoxetine promoted the apoptosis effect of paclitaxel. To further verify the cell death mechanism, we analyzed treated cells by Annexin V/PI staining in flow cytometry. According to Annexin V/PI staining, following treatment with the combination of fluoxetine and paclitaxel, there was a significant difference in early apoptotic cells relative to single treatment with paclitaxel. However, late apoptotic cell death increased in the group treated with the combination of these drugs. One study has reported that RIP3 catalytic activity was dispensable for apoptosis but essential for necroptosis and 

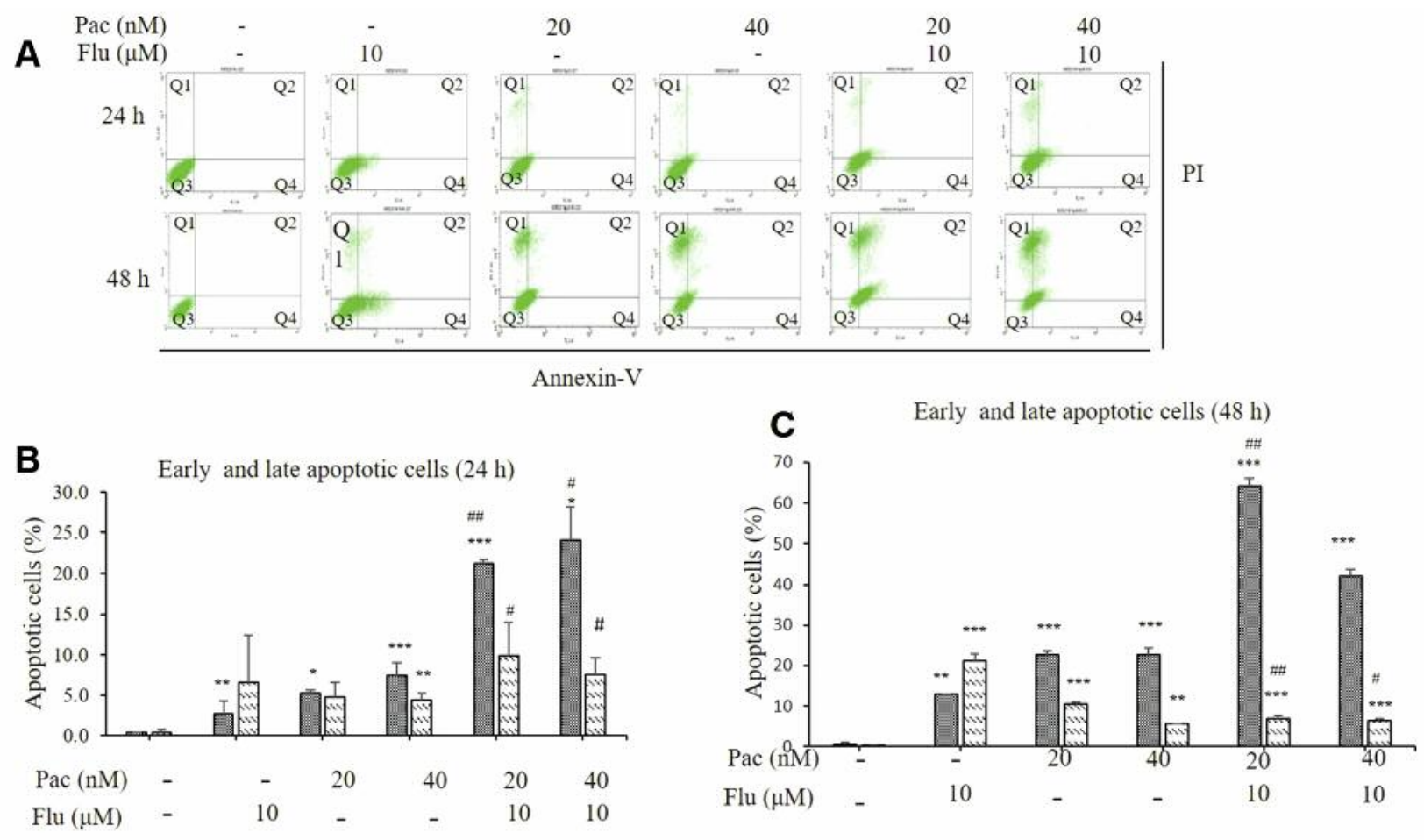

- Late apoptosis $\quad$ Early apoptotic cells

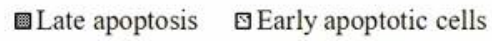

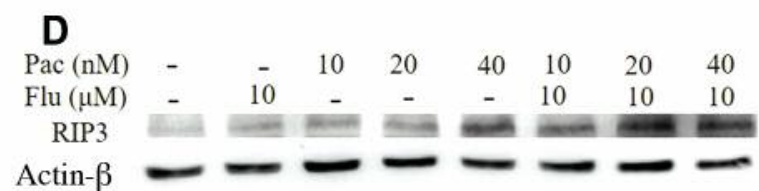

Figure 5. Effects of paclitaxel (Pac) and fluoxetine (Flu) alone or in combination on apoptosis and necroptosis. (A) Apoptotic cells were determined by flow cytometry following Annexin V-fluorescein isothiocyanate/propidium iodide (PI) staining after $24 \mathrm{~h}$ and $48 \mathrm{~h}$ treatment with paclitaxel and fluoxetine in which $Q 1=$ necrotic cells, $Q 2=$ late apoptotic cells, $Q 3=$ live cells and $Q 4=$ early apoptotic cells $(B, C)$ Quantitative analysis of early and late apoptotic cells. (D) The AGS cells were treated individually with 10,20, and $40 \mathrm{nM}$ paclitaxel, or in combination with $10 \mu \mathrm{M}$ fluoxetine for $24 \mathrm{~h}$ and RIP3 expression was determined by western blot analysis. $\beta$-Actin was used as the loading control. The data are presented as the mean $\pm S . E . M, n=3 ;$ were analyzed using a one-way ANOVA test. $\left({ }^{*} p<0.05, * * p<0.01 * * * p<0.001\right.$ compared with the untreated group, ${ }^{\#} p<0.05$ and ${ }^{\# \#} p<0.01$ compared with individual treatment group).

both apoptosis and necroptosis could proceed simultaneously (27). It was suggested that paclitaxel alone or in combination caused necroptotic and apoptotic cell death simultaneously. To confirm the induction of necroptosis, we studied RIP3 protein expression after treatment of AGS cells, using western blotting. RIP3 protein expression increased in cells treated with paclitaxel alone or in combination with fluoxetine.

Two major apoptotic signaling pathways exist in mammalian cells: The intrinsic pathway, which is controlled by the Bcl-2 family of proteins and is induced by chemotherapy and radiotherapy, and the extrinsic pathway, which is mediated by the TNF receptor superfamily (28). To further examine the apoptotic effect of single and combination treatments, western blot analysis was performed to determine the levels of DR4, DR5, and PARP protein expression. In the combination-treated cells, PARP expression was increased compared to that in the single agent treated cells. Moreover, it has been previously suggested that the PARP pathway is an integral part of TNFinduced necroptosis in L929 fibrosarcoma cells (29). Therefore, it was suggested that increased levels of cleaved PARP are involved in apoptosis and necroptosis. There was no significant difference in DR4 protein expression relative to that in the nontreated group. DR5 protein expression was increased in the combination treatment group. Therefore, it is suggested that the TRAIL receptor DR5 is involved in one of the apoptotic cell death mechanisms in treated cells. It has been reported that paclitaxel down-regulates Bcl-2 and activates caspases and PARP (30). This is in agreement with our study in which proapoptotic protein $\mathrm{Bcl}-2$ expression decreased and PARP and caspase activity increased in combination-treated cells 

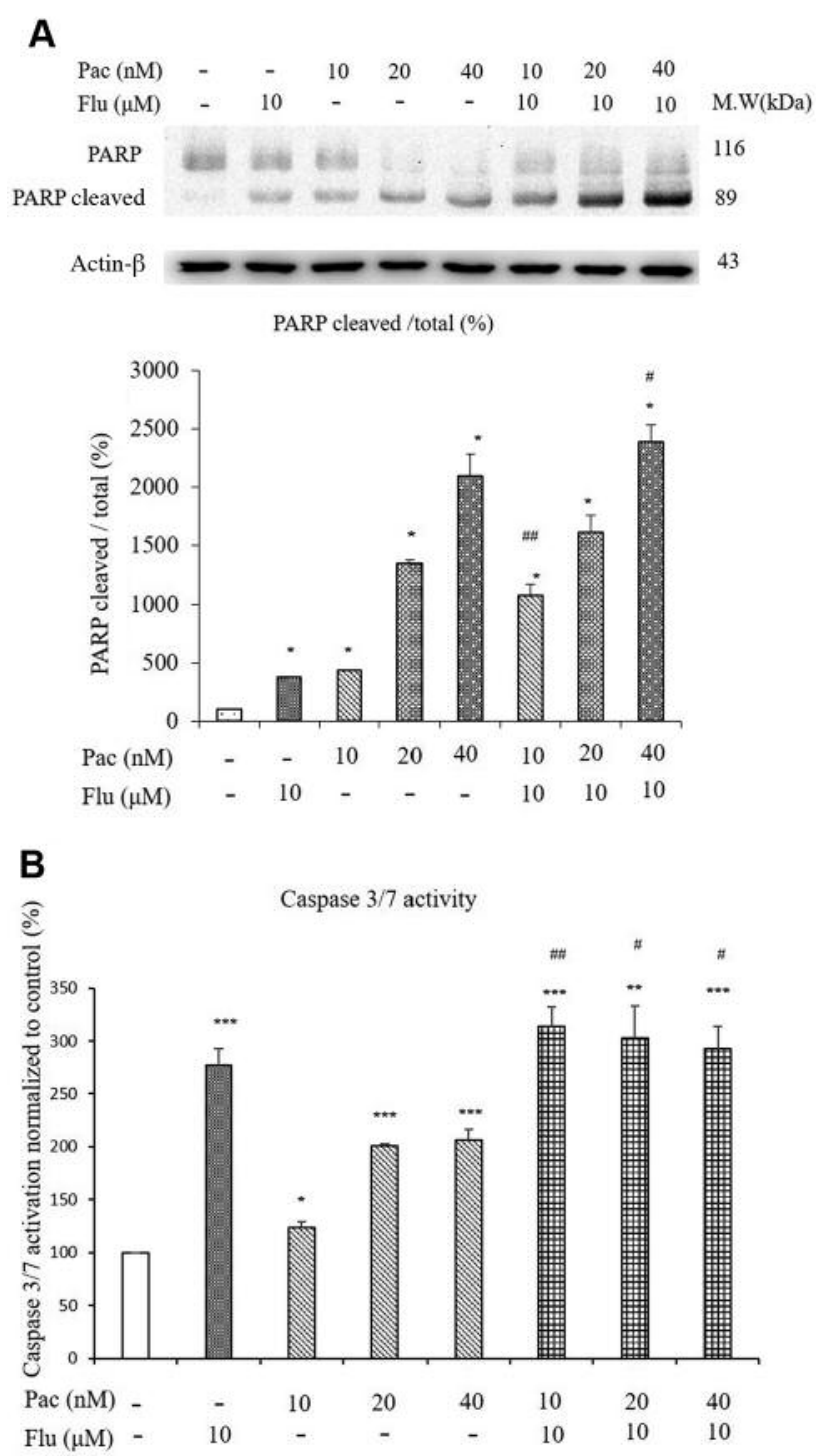

Figure 6. Fluoxetine enhances the apoptotic effect of paclitaxel in AGS cells. (A) AGS cells were treated with paclitaxel (Pac) alone or in combination with fluoxetine (Flu) for $24 \mathrm{~h}$ and the expression of PARP and cleaved PARP were determined by western blot analysis. $\beta$-Actin was used as the loading control. The protein bands were quantified by densitometry. (B) AGS cells treated as previously [mentioned in Figure (A)] in 96-well plates were incubated with $100 \mu$ l of Caspase-Glo ${ }^{\circledR}$ 3/7 reagent for $1 \mathrm{~h}$, and the luminescence was measured for determining caspase 3/7 activity. The data are presented as the mean \pm S.E.M, $n=3$; were analyzed using one-way ANOVA test. $\left({ }^{*} p<0.05\right.$ compared with the non-treated group and ${ }^{\#} p<0.05$ compared with single treatment group).

compared to cells treated with one of the drugs. In contrast, fluoxetine enhanced the anti- proliferative effect of paclitaxel by decreasing phosphorylation of Erk $1 / 2$ and Akt. Moreover, fluoxetine enhanced the apoptotic effect of paclitaxel by activating caspase-3/7 and PARP. In addition to apoptosis, the



Figure 7. The role of the TRAIL receptor DR5 in paclitaxel (Pac) and fluoxetine (Flu)-mediated effects on AGS cells. AGS cells were treated with paclitaxel alone or in combination with fluoxetine for $24 \mathrm{~h}$ and DR5, DR4, and Bcl-2 expression levels were determined by western blot analysis. $\beta$-Actin was used as loading control.

fluoxetine-paclitaxel combination caused an increase in necroptotic cell death. Therefore, the mechanism of the effect of paclitaxel on necroptosis in gastric cancer cells needs to be studied in detail.

\section{Conflicts of interest}

The Authors have no conflict of interest to declare regarding this study.

\section{Authors' Contributions}

UDS and TMK conceived the idea for the project and planned the experiments. TMK performed all the experiments and drafted the manuscript under the supervision of UDS. WWP, TMK and UDS discussed the results and reviewed the manuscript prior to submission.

\section{Acknowledgements}

The research was supported by the Basic Science Research Program through the National Research Foundation of Korea (NRF) and funded by the Ministry of Education, Science and Technology [Grant 2016R1D1A1A09918019].

\section{References}

1 Mitchell AJ, Chan M, Bhatti H, Halton M, Grassi L, Johansen $\mathrm{C}$ and Meader N: Prevalence of depression, anxiety, and adjustment disorder in oncological, haematological, and palliative-care settings: A meta-analysis of 94 interview-based studies. Lancet Oncol 12(2): 160-174, 2011. PMID: 21251875. DOI: $10.1016 / \mathrm{S} 1470-2045(11) 70002-\mathrm{X}$

2 Caruso R, GiuliaNanni M, Riba MB, Sabato S and Grassi L: Depressive spectrum disorders in cancer: Diagnostic issues and intervention. A critical review. Curr Psychiatry Rep 19(6): 33, 2017. PMID: 28488207. DOI: 10.1007/s11920-017-0785-7

3 Kampan NC, Madondo MT, McNally OM, Quinn M and Plebanski M: Paclitaxel and its evolving role in the management of ovarian cancer. Biomed Res Int 2015: 413076, 2015. PMID: 26137480. DOI: $10.1155 / 2015 / 413076$ 
4 Gong JF, Lu M, Li J, Li Y, Zhou J, Lu ZH, Wang XC, Li J, Zhang XT and Shen L: Efficacy of albumin-bound paclitaxel in advanced gastric cancer patients. Beijing Da Xue Xue Bao Yi Xue Ban 46(1): 144-148, 2014. PMID: 24535367.

5 Liu H, Wang J, Sheng L, Zhang Y, Tang N, Li Y and Hao T: Paclitaxel promotes cell apoptosis in uterine leiomyomas. Pharmacology 100(5-6): 246-252, 2017. PMID: 28793305. DOI: $10.1159 / 000479161$

6 Ren Y, Wang X, Lou Z, Huang S, Zhuang H, Wang Y, Weng G and Wang P: Induction of cell cycle arrest by increasing gtprhoa levels via taxolinduced microtubule polymerization in renal cell carcinoma. Mol Med Rep 15(6): 4273-4279, 2017. PMID: 28487984. DOI: $10.3892 / \mathrm{mmr} .2017 .6543$

7 Weaver BA: How taxol/paclitaxel kills cancer cells. Mol Biol Cell 25(18): 2677-2681, 2014. PMID: 25213191. DOI: 10.1091/ mbc.E14-04-0916

8 Diao Y, Ma X, Min W, Lin S, Kang H, Dai Z, Wang X and Zhao Y: Dasatinib promotes paclitaxel-induced necroptosis in lung adenocarcinoma with phosphorylated caspase- 8 by c-src. Cancer Lett 379(1): 12-23, 2016. PMID: 27195913. DOI: 10.1016/ j.canlet.2016.05.003

9 Nakanishi K, Kobayashi D, Mochizuki Y, Ishigure K, Ito S, Kojima H, Ishiyama A, Fujitake S, Shikano T, Morita S and Kodera Y: Phase II multi-institutional prospective randomized trial comparing s-1 plus paclitaxel with paclitaxel alone as second-line chemotherapy in s-1 pretreated gastric cancer (ccog0701). Int J Clin Oncol 21(3): 557-565, 2016. PMID: 26547424. DOI: 10.1007/s10147-015-0919-z

10 Lin YM, Yu BC, Chiu WT, Sun HY, Chien YC, Su HC, Yen SY, Lai HW, Bai $\mathrm{CH}$, Young $\mathrm{KC}$ and Tsao CW: Fluoxetine regulates cell growth inhibition of interferon-alpha. Int J Oncol 49(4): 17461754, 2016. PMID: 27499259. DOI: 10.3892/ijo.2016.3650

11 Mun AR, Lee SJ, Kim GB, Kang HS, Kim JS and Kim SJ: Fluoxetine-induced apoptosis in hepatocellular carcinoma cells. Anticancer Res 33(9): 3691-3697, 2013. PMID: 24023297.

12 Krishnan A, Hariharan R, Nair SA and Pillai MR: Fluoxetine mediates $\mathrm{g} 0 / \mathrm{g} 1$ arrest by inducing functional inhibition of cyclin dependent kinase subunit (cks)1. Biochem Pharmacol 75(10): 19241934, 2008. PMID: 18371935. DOI: 10.1016/j.bcp.2008.02.013

13 Chen WT, Hsu FT, Liu YC, Chen CH, Hsu LC and Lin SS: Fluoxetine induces apoptosis through extrinsic/intrinsic pathways and inhibits erk/nf-kappab-modulated anti-apoptotic and invasive potential in hepatocellular carcinoma cells in vitro. Int J Mol Sci 20(3), 2019. PMID: 30754643. DOI: 10.3390/ijms 20030757

14 Kerr JFR, Wyllie AH and Currie AR: Apoptosis: A basic biological phenomenon with wideranging implications in tissue kinetics. Br J Cancer 26(4): 239-257, 1972. PMID: 4561027. DOI: $10.1038 /$ bjc.1972.33

15 Morgan DO: Principles of cdk regulation. Nature 374(6518): 131-134, 1995. PMID: 7877684. DOI: 10.1038/374131a0

16 Wang T, Jin Y, Yang W, Zhang L, Jin X, Liu X, He Y and Li X: Necroptosis in cancer: An angel or a demon? Tumour Biol 39(6): 1010428317711539, 2017. PMID: 28651499. DOI: 10.1177/ 1010428317711539

17 Hong SK, Wu PK and Park JI: A cellular threshold for active erk1/2 levels determines raf/mek/erk-mediated growth arrest versus death responses. Cell Signal 42: 11-20, 2018. PMID: 28986121. DOI: $10.1016 /$ j.cellsig.2017.10.001

18 Ebbesen SH, Scaltriti M, Bialucha CU, Morse N, Kastenhuber ER, Wen HY, Dow LE, Baselga $\mathrm{J}$ and Lowe SW: Pten loss promotes mapk pathway dependency in her2/neu breast carcinomas. Proc Natl Acad Sci USA 113(11): 3030-3035, 2016. PMID: 26929372. DOI: 10.1073/pnas.1523693113

19 Bhaskar PT and Hay N: The two torcs and akt. Dev Cell 12(4): 487502, 2007. PMID: 17419990. DOI: 10.1016/j.devcel.2007.03.020

20 Feoktistova $M$ and Leverkus M: Programmed necrosis and necroptosis signalling. FEBS J 282(1): 19-31, 2015. PMID: 25327580. DOI: $10.1111 /$ febs. 13120

21 Jung K-W, Won Y-J, Kong H-J and Lee ES: Prediction of cancer incidence and mortality in korea, 2018. Cancer Res Treat 50(2): 317-323, 2018. PMID: 29566480. DOI: $10.4143 /$ crt.2018.142

22 Sanjida S, Janda M, Kissane D, Shaw J, Pearson SA, DiSipio T and Couper J: A systematic review and meta-analysis of prescribing practices of antidepressants in cancer patients. Psychooncology 25(9): 1002-1016, 2016. PMID: 26775715. DOI: 10.1002/pon.4048

23 Choi JH, Jeong YJ, Yu AR, Yoon KS, Choe W, Ha J, Kim SS, Yeo EJ and Kang I: Fluoxetine induces apoptosis through endoplasmic reticulum stress via mitogen-activated protein kinase activation and histone hyperacetylation in sk-n-be(2)-m17 human neuroblastoma cells. Apoptosis 22(9): 1079-1097, 2017. PMID: 28647884. DOI: 10.1007/s10495-017-1390-2

24 Kawada J, Nishino M, Hosoda Y, Hoshino H, Okano M, Nagai K, Okuyama M, Kim Y and Tsujinaka T: Analysis of 5fluorouracil and leucovorin combined with weekly paclitaxel in advanced gastric cancer. Gan To Kagaku Ryoho 43(12): 19511953, 2016. PMID: 28133186.

25 Yang SX, Costantino JP, Kim C, Mamounas EP, Nguyen D, Jeong JH, Wolmark N, Kidwell K, Paik S and Swain SM: Akt phosphorylation at ser473 predicts benefit of paclitaxel chemotherapy in node-positive breast cancer. J Clin Oncol 28(18): 2974-2981, 2010. PMID: 20479407. DOI: 10.1200/ jco.2009.26.1602

26 Das GC, Holiday D, Gallardo R and Haas C: Taxol-induced cell cycle arrest and apoptosis: Dose-response relationship in lung cancer cells of different wild-type p53 status and under isogenic condition. Cancer Lett 165: 147-153, 2001. PMID: 11275363. DOI: $10.1016 / \mathrm{s} 0304-3835(01) 00404-9$

27 Cook WD, Moujalled DM, Ralph TJ, Lock P, Young SN, Murphy JM and Vaux DL: Ripk1- and ripk3-induced cell death mode is determined by target availability. Cell Death Differ 21(10): 16001612, 2014. PMID: 24902899. DOI: $10.1038 / \mathrm{cdd} .2014 .70$

$28 \mathrm{Xu} \mathrm{X}$, Lai Y and Hua ZC: Apoptosis and apoptotic body: Disease message and therapeutic target potentials. Biosci Rep 39(1): BSR20180992, 2019. PMID: 30530866. DOI: 10.1042/ bsr20180992

29 Los M, Mozoluk M, Ferrari D, Stepczynska A, Stroh C, Renz A, Herceg Z, Wang ZQ and Schulze-Osthoff K: Activation and caspase-mediated inhibition of parp: A molecular switch between fibroblast necrosis and apoptosis in death receptor signaling. Mol Biol Cell 13(3): 978-988, 2002. PMID: 11907276. DOI: $10.1091 / \mathrm{mbc} .01-05-0272$

30 Lim SJ, Choi MK, Kim MJ and Kim JK: Alpha-tocopheryl succinate potentiates the paclitaxel-induced apoptosis through enforced caspase 8 activation in human h460 lung cancer cells. Exp Mol Med 41(10): 737-745, 2009. PMID: 19561399. DOI: 10.3858/emm.2009.41.10.080

Received October 7, 2019

Revised October 24, 2019 Accepted October 25, 2019 